\title{
Carotid blowout syndrome after nasopharyngeal carcinoma radiotherapy: successful treatment by internal carotid artery occlusion after stent implantation failure
}

Fei Dong, Qian Li, JianJun Wu, MinMing Zhang, GuangQiang Zhang, Bin Li, Kai Jin, Jie Min, WeiRen Liang and Ming Chao*

\begin{abstract}
Introduction: Carotid blowout syndrome (CBS) secondary to radiation therapy is life-threatening and requires emergency treatment. More recently, endovascular treatment has provided an effective way to control CBS-related bleeding.

Case description: We present a case of CBS with a rupture of the internal carotid artery (ICA) pseudo-aneurysm after Gamma Knife radiation therapy for nasopharyngeal carcinoma (NPC). The patient was a 55-year-old man who was transferred to our hospital with severe repetitive epistaxis. He had a history of NPC and had been treated with Gamma Knife radiation therapy 7 months prior, with a central dose of 32 Gy and marginal dose of 16 Gy. As CBS was confirmed by angiography, and the affected part of the ICA lumen exhibited moderate stenosis, the patient was successfully treated by ICA occlusion after stent implantation failure. The patient died 40 months after this operation from tumor recurrence, but without epistaxis during follow up.
\end{abstract}

Discussion and Evaluation: Quick selection of an appropriate treatment method is very important for an acute CBS patient.

Conclusion: ICA occlusion can be directly considered for an acute CBS patient, if the affected ICA exhibits stenosis that is moderate or above.

Keywords: Carotid blowout syndrome, Endovascular treatment, Radiotherapy, Internal carotid artery

\section{Background}

Carotid blowout syndrome (CBS) is an uncommon, lifethreatening complication in patients with radiation therapy for nasopharyngeal carcinoma (NPC) that requires emergency treatment. More recently, endovascular treatment has provided an effective way to control the bleeding associated with carotid blowout syndrome. In previous works, some researchers have suggested that stent placement is safe and feasible for this disease (Hakime et al. 2013; Farivar et al. 2014), and some argued that endovascular

\footnotetext{
*Correspondence: doctor_chaoming@163.com

Department of Radiology, The Second Affiliated Hospital, Zhejiang University School of Medicine, Hangzhou 310009, China
}

embolization provides both safe and effective management (He et al. 2013). Additionally, some researchers have found that there was no significant difference in the technical and hemostatic outcomes of stent placement and endovascular embolization (Chang et al. 2008). Here, we report a case of CBS secondary to Gamma Knife radiation therapy for nasopharyngeal carcinoma that was successfully treated by ICA occlusion after stent implantation failure.

\section{Case report}

This study was approved by the Institutional Review Board and conformed with the principles outlined in the Declaration of Helsinki. A 55-year-old man was transferred to our hospital with severe repetitive epistaxis that had been 
occurring for $16 \mathrm{~h}$. He had a history of NPC and had been treated with Gamma Knife radiotherapy 7 months prior. The central dose was $32 \mathrm{~Gy}$, and the marginal dose was $16 \mathrm{~Gy}$. He had no history of head and neck trauma. On admission to our hospital, physical examination showed a blood pressure of 106/78 mmHg, pulse rate of 150 beats per minute, and nasal bleeding. Blood test results were normal, except values for hemoglobin $(\mathrm{Hb})(7.7 \mathrm{~g} / \mathrm{dL})$, platelet count $(114,000 / \mu \mathrm{L})$, prothrombin time $(14.7 \mathrm{~s})$, and plasma fibrinogen $(1.2 \mathrm{~g} / \mathrm{L})$. Despite performing anterior and posterior nasal packing, approximately $400 \mathrm{~mL}$ of blood discharged from his mouth and nasal cavity $2 \mathrm{~h}$ later. Wadding was compressed, but massive oral and nasal bleeding emerged again $8 \mathrm{~h}$ later. His blood pressure dropped to $80 / 45 \mathrm{mmHg}$ and pulse rate rose to 160 beats per minute. The patient was stabilized by continuous oxygen and massive intravenous serum infusion.

As CBS was suspected, digital subtraction angiography was performed. A pseudo-aneurysm approximately $17 \mathrm{~mm} \times 10 \mathrm{~mm}$ in size was identified in the middle portion of the right internal carotid artery at the nasopharyngeal level, with adjacent parent vessel stenosis (Fig. 1). As the bleeding was repetitive and massive, we decided to use endovascular treatment. An emergency ICA compression test was performed, and it showed good compensatory blood flow from the Circle of Willis (Fig. 2). We then tried to implant a covered stent,

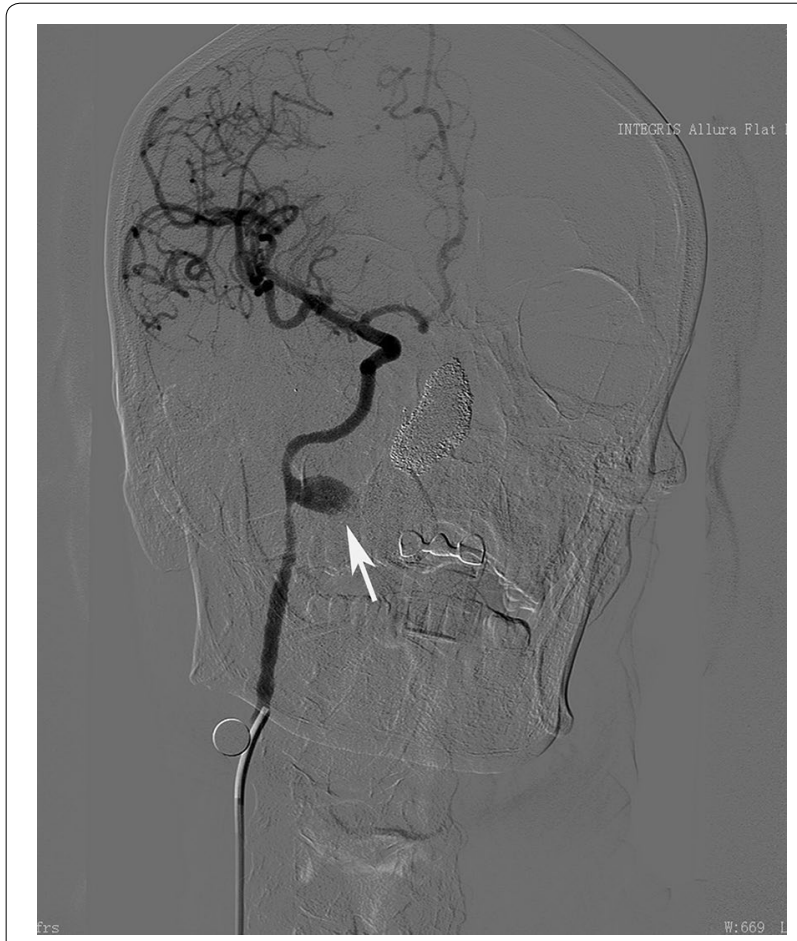

Fig. 1 The angiogram shows a pseudo-aneurysm (white arrow) in the middle part of the right internal carotid artery at the nasopharyngeal level with the adjacent parent vessel, exhibiting moderate stenosis

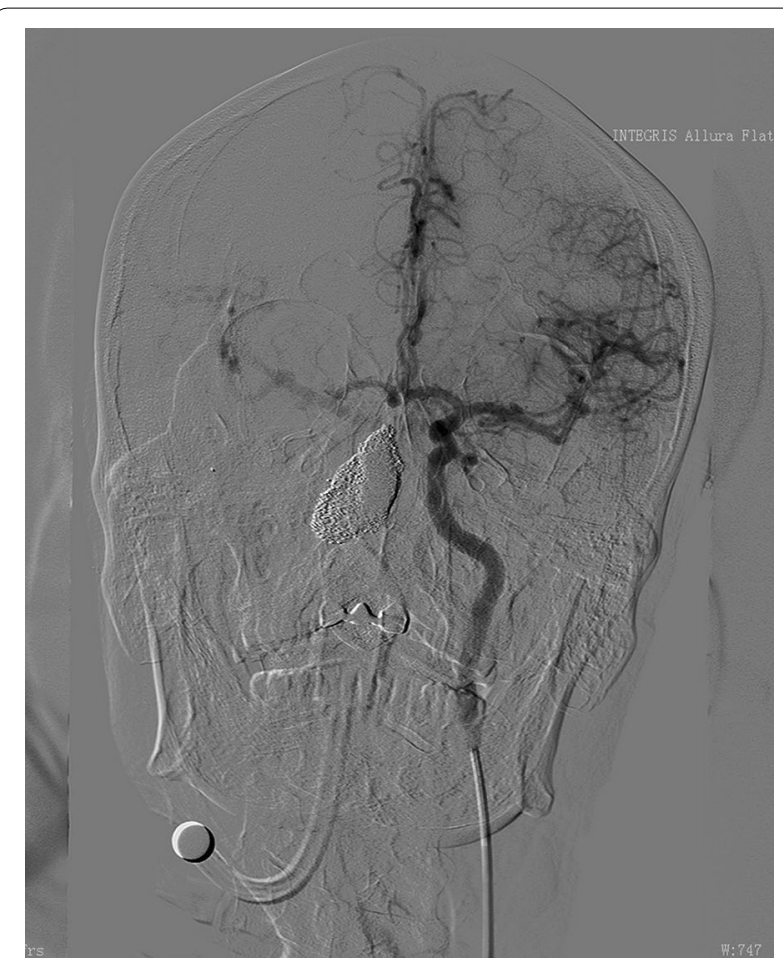

Fig. 2 The angiogram shows good contralateral compensatory blood flow from the Circle of Willis when performing the compression test of the right ICA

which failed because of the narrow lumen. Massive bleeding occurred during the procedure. We immediately occluded the right ICA with coils, and the pseudo-aneurysm disappeared with the bleeding controlled (Fig. 3).

After ICA occlusion, the vital signs of the patient were stable. However, blood pressure began gradually dropping and ventricular escape rhythm occurred after $1 \mathrm{~h}$. Symptomatic treatment was given, and he gradually recovered, though with some symptoms of paralysis. The patient died 40 months after this operation from tumor recurrence, but without epistaxis during follow up.

\section{Discussion}

Carotid blowout syndrome (CBS) has been defined as the rupture of the carotid artery associated with hemorrhage or exposure of part of the carotid artery in a patient who has undergone aggressive management for head and neck cancer. Irradiation, radical surgery of head and neck tumors, and persistent or recurrent tumors are common predisposing factors for CBS (Luo et al. 2008; Yanik et al. 2011).

The formation mechanism of CBS after radiation therapy may be due to radiation-induced vascular injury, which may result from obliteration of the vasa vasorum, 


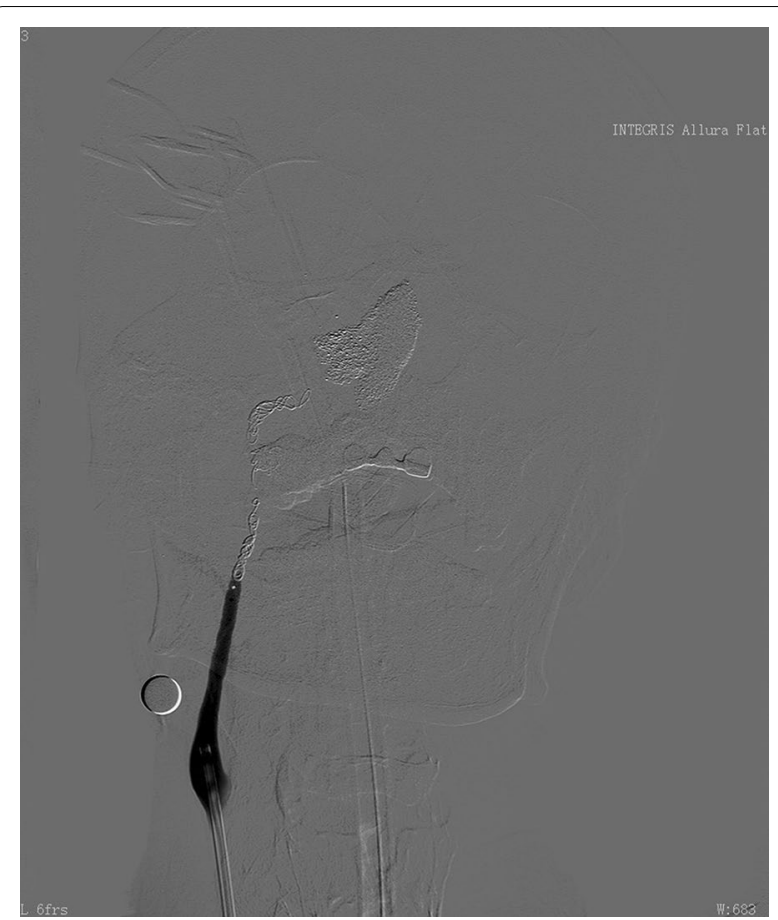

Fig. 3 The angiogram shows that the pseudo-aneurysm disappears after ICA occlusion with microcoils, and there is no sign of bleeding

premature atherosclerosis, and weakening and necrosis of the arterial wall (Okamura et al. 2002). The mortality rate of carotid blowout after re-irradiation in head and neck cancer patients, according to a recent meta-analysis, was as high as $76 \%$ (McDonald et al. 2012). It is reported that a total radiation dose to the neck $\geq 70$ Gy is an independent risk factor associated with CBS (Chen et al. 2015). The radiation dose for our case was much less than 70 Gy. We speculate this risk may be due to the more intensive radiation with Gamma Knife than conventional radiotherapy.

Carotid blowout syndrome can present as one of three separate entities: threatened, impending, or acute carotid blowout (Cohen and Rad 2004). The present case was acute carotid blowout when admitted, and the bleeding was difficult to control by conventional methods. Thus, quick diagnosis and effective treatment are very important for this disease.

Angiography has been considered the gold standard for the diagnosis of CBS since the 1980s (Cohen and Rad 2004). We believe that once repetitive bleeding occurs in a patient with a head and neck neoplasm radiation history, carotid blowout syndrome should be suspected, and angiography should be performed as quickly as possible for further confirmation.

Emergency surgical ligation has traditionally been the only therapeutic maneuver available for CBS (Chaloupka et al. 1996). The mortality and morbidity rates of surgical ligation for acute hemorrhage patients are very high and can reach 40 and $60 \%$, respectively (Chaloupka et al. 1996).

More recently, endovascular treatment has provided an effective way to control the bleeding associated with carotid blowout syndrome. This method mainly includes two approaches; one is embolizing the vessel with detachable balloons or coils, and the other is preserving the vessel by stent, to cover the affected wall (Farivar et al. 2014).

Using covered stents for reconstruction of the affected ICA, at least in theory, is a more desirable treatment option, preserving patency of the carotid artery. However, stents cannot be successfully implanted in all patients (Haas and Ahn 2013). For the present case, stent implantation was initially chosen but failed because of moderate lumen stenosis and the emergent massive bleeding that occurred during the procedure due to the weakened vascular structure. We thought that the degree of lumen stenosis of the affected part of the ICA might be an important factor affecting stent implantation. If the lumen stenosis is moderate or above, stent implantation may be difficult.

Endovascular embolization allows occlusion of the affected ICA and is advantageous over stent implantation in its low rates of technical complications and rebleeding (Chang et al. 2015). However, embolizing the ICA may lead to severe cerebrovascular events. To ensure patient safety, performing a balloon test occlusion (BTO) is advocated prior to sacrificing the vessel (Haas and Ahn 2013). However, BTO is not always reliable. In a review of 8 years experience literature, $20 \%$ ( 1 out of 5 ) of patients who passed the BTO had a cerebrovascular event (transient ischemic attack) after the ICA occlusion (Wan et al. 2013), and the probability of a cerebrovascular event is equal to those patients who were excluded from the BTO ( 1 out of 5 , with left hemiplegia). Some authors have even proposed that in certain patients, BTO may be bypassed due to the emergency of the clinical situation (Haas and Ahn 2013). Our patient was in an emergency situation; the balloon test occlusion was not possible and only a carotid artery compression test was used as a substitute, but it too may be unreliable.

Despite all efforts, our case suffered transient cerebral ischemia $1 \mathrm{~h}$ after the operation. We believe that this event was associated with hypovolemia, vasospasm alleviation and compensatory insufficiency, which led to the dysfunction of cerebral autoregulation. Therefore, careful observation and symptomatic treatment to maintain stable systemic blood pressure is very important.

\section{Conclusions}

In conclusion, carotid blowout syndrome secondary to radiation therapy is rare but life-threatening. Compared to conventional radiotherapy, a lower radiation dose may 
induce CBS in patients with Gamma Knife treatment for NPC. ICA occlusion can be directly considered if the affected ICA stenosis is moderate or above. Maintaining systemic blood pressure should be an important step to prevent ischemic complications after unilateral ICA occlusion.

\section{Authors' contributions}

DF, LQ and JK drafted the manuscript. WJJ, ZMM, ZGQ, LB, MJ and LWR revised critically the article. ZMM participated in the design of the study. CM conceived of the study, and participated in its design and coordination. All authors read and approved the final manuscript.

\section{Competing interests}

The authors declare that they have no competing interests.

\section{Funding}

Fei Dong has supported by projects of medicine and health scientific and technological program of Zhejiang province, China (2016KYA104).

\section{Patient consent}

The patient and his immediate family had given their consent for the use of his personal and medical information for the publication of this study and any accompanying images.

Received: 19 September 2015 Accepted: 2 September 2016

Published online: 13 September 2016

\section{References}

Chaloupka JC, Putman CM, Citardi MJ, Ross DA, Sasaki CT (1996) Endovascular therapy for the carotid blowout syndrome in head and neck surgical patients: diagnostic and managerial considerations. AJNR Am J Neuroradiol 17:843-852

Chang FC, Lirng JF, Luo CB, Wang SJ, Wu HM, Guo WY, Teng MM, Chang CY (2008) Patients with head and neck cancers and associated postirradiated carotid blowout syndrome: endovascular therapeutic methods and outcomes. J Vasc Surg 47:936-945. doi:10.1016/j.jvs.2007.12.030
Chang FC, Luo CB, Lirng JF, Lin CJ, Lee HJ, Wu CC, Hung SC, Guo WY (2015) Endovascular management of post-irradiated carotid blowout syndrome. PLOS ONE 10:e0139821. doi:10.1371/journal.pone.0139821

Chen YJ, Wang CP, Wang CC, Jiang RS, Lin JC, Liu SA (2015) Carotid blowout in patients with head and neck cancer: associated factors and treatment outcomes. Head Neck 37:265-272. doi:10.1002/hed.23590

Cohen J, Rad I (2004) Contemporary management of carotid blowout. Curr Opin Otolaryngol Head Neck Surg 12:110-115

Farivar BS, Lee DH, Khalil A, Abrol S, Flores L (2014) Carotid blowout syndrome: endovascular management of acute hemorrhage with tapering overlapped covered stents. Ann Vasc Surg 28:1934. doi:10.1016/j. avsg.2014.06.075

Haas RA, Ahn SH (2013) Interventional management of head and neck emergencies: carotid blowout. Semin Intervent Radiol. 30:245-248. doi:10.105 5/s-0033-1353477

Hakime A, Khoury E, Hameg A, Liberge R, Deschamps F, Farouil G, Joskin J, Tselikas L, Temam S, Janot F, De Baere T (2013) Polytetrafluoroethylenecovered nitinol stent graft for treatment of carotid artery blowout syndrome in head and neck cancer patients. Laryngoscope 123:1670-1675. doi:10.1002/lary.24006

He CC, Si YF, Xie YA, Yu L (2013) Management of intractable epistaxis in patients who received radiation therapy for nasopharyngeal carcinoma. Eur Arch Otorhinolaryngol 270:2763-2767. doi:10.1007/s00405-013-2598-6

Luo CB, Teng MM, Chang FC, Chang CY, Guo WY (2008) Radiation carotid blowout syndrome in nasopharyngeal carcinoma: angiographic features and endovascular management. Otolaryngol Head Neck Surg 138:86-91. doi:10.1016/j.otohns.2007.10.013

McDonald MW, Moore MG, Johnstone PA (2012) Risk of carotid blowout after reirradiation of the head and neck: a systematic review. Int J Radiat Oncol Biol Phys 82:1083-1089. doi:10.1016/j.jprobp.2010.08.029

Okamura HO, Kamiyama R, Takiguchi Y, Kimizuka K, Ishikawa N, Kishimoto S (2002) Histopathological examination of ruptured carotid artery after irradiation. ORL J Otorhinolaryngol Relat Spec 64:226-228

Wan WS, Lai V, Lau HY, Wong YC, Poon WL, Tan CB (2013) Endovascular treatment paradigm of carotid blowout syndrome: review of 8-years experience. Eur J Radiol 82:95-99. doi:10.1016/j.jejrad.2011.01.061

Yanik B, Keyik B, Conkbayir I, Teber MA (2011) Carotid blowout syndrome with oronasal hemorrhage: magnetic resonance imaging findings. Jpn J Radiol 29:72-75. doi:10.1007/s11604-010-0503-4

\section{Submit your manuscript to a SpringerOpen ${ }^{\circ}$ journal and benefit from:}

- Convenient online submission

- Rigorous peer review

- Immediate publication on acceptance

- Open access: articles freely available online

- High visibility within the field

- Retaining the copyright to your article

Submit your next manuscript at $\boldsymbol{\nabla}$ springeropen.com 